\title{
A REFORMA DA PREVIDÊNCIA E A QUESTÃO DOS DIREITOS ADQUIRIDOS EM FACE DAS REGRAS DE TRANSIÇÃO
}

\author{
ANA FRAZÃO DE AZEVEDO LOPES*
}

\begin{abstract}
1. Introdução. 2. A distinção entre direitos adquiridos e expectativas de direito. 3. A natureza jurídica e as finalidades das regras de transição não se compatibilizam com a possibilidade de revogação superveniente. 4. A EC $n^{\circ} 20 / 98$, ao prever as regras de transição, criou verdadeiros direitos adquiridos sob condição, o que é perfeitamente possivel e legítimo. 5. $O$ direito à aposentadoria é de aquisição complexa: os fatos aquisitivos constituidos sob a égide de uma norma constitucional não podem ser desconsiderados pela norma superveniente. 6. Considerações finais.
\end{abstract}

\section{Introdução}

O advento da Emenda Constitucional $n^{\circ} 41 / 2003$ trouxe à discussão a delicada questão do direito adquirido em face de regras de transição, especialmente diante do fato de a aposentadoria ser um direito de aquisição sucessiva no tempo.

A razão da controvérsia decorre da circunstância de que a anterior Emenda Constitucional $\mathrm{A}^{2} 20 / 98$ previu, em seu art. $8^{\circ}$, regras específicas de transição para aqueles que já eram servidores na data sua publicação. Dessa maneira, disciplinou o direito ă aposentadoria voluntária destes servidores com base em limites de idade, tempo no cargo e tempo de contribuição mais benéficos.

Assim, como a EC $n^{\circ} 20$ foi publicada em 16.12.98, tem-se que todos os servidores que ocupavam cargos públicos nesta data foram excetuados das novas regras de aposentadoria, passando a ter o seu direito regido pela sistemática delineada nas regras de transição.

Não obstante, a superveniente Emenda Constitucional $n^{\circ} 41 / 2003$, em seus arts. $2^{\circ}$ e 10 , revogou o art. $8^{\circ}$, da EC 20/98, alterando as regras de transição para os

* Advogada, Mestre em Direito e Estado pela Universidade de Brasília - UnB.

R. Dir. Adm.,

Rio de Janeiro, 238: 17-35,

Out./Dez. 2004 
servidores que já ocupavam cargos públicos em 16.12.98, sem considerar nem mesmo os fatos já constituídos sob a vigência da anterior emenda constitucional.

Em face da EC n ${ }^{\circ} 41 / 2003$, surge a necessidade de saber se teria havido uma mera frustração das expectativas de direito dos servidores ocupantes de cargos públicos em 16.12 .98 ou se teria havido uma verdadeira violação ao direito adquirido dos referidos servidores.

Não se pode esquecer que o princípio constitucional que resguarda o direito adquirido ( $\mathrm{CF}$, art. $\left.5^{\circ}, \mathrm{XXXV}\right)$ é garantia fundamental e cláusula pétrea da Constituição. Conseqüentemente, não pode ser alterado ou mitigado por emenda constitucional, como deixa claro o art. $60, \S 4^{\circ}, \mathrm{IV}$, da CF.

É diante desta controvérsia que procura o presente artigo oferecer alguns subsídios à discussão, explorando as particularidades da questão, especialmente no que se refere à natureza jurídica das regras de transição e do direito à aposentadoria.

\section{A distinção entre direitos adquiridos e expectativas de direito}

A doutrina mais autorizada sobre o direito intertemporal distingue o direito adquirido da expectativa de direito com base na existência de um fato, previsto diretamente na lei ou não, capaz de converter uma previsão de direito objetivo (mera expectativa) em um direito subjetivo.

É por essa razão que Limongi França define o direito adquirido como " $a$ consequiência de uma lei, por via direta ou por intermédio de fato idôneo; conseqüência que, tendo passado a integrar o patrimônio material ou moral do sujeito, não se fez valer antes da vigência de lei nova sobre o mesmo objeto." 1

Conseqüentemente, esclarece o autor que "a diferença entre expectativa de direito e direito adquirido está na existência, em relação a este, do fato aquisitivo específico, já configurado por completo", aduzindo, em seguida, que "é preciso porém esclarecer que o fato aquisitivo específico não é só o fato particular, exterior à lei; diversamente, ele também se pode encontrar na própria lei, se se trata de direito adquirido por virtude direta da própria norma legal." 2

No mesmo sentido, sustenta Carlos Maximiliano que "fato capaz de transmudar um direito objetivo e abstrato em um subjetivo e concreto é indispensável para criar direito adquirido" 3 , ressaltando, todavia, que, dentre os fatos que geram direitos, estão os "involuntários e fortuitos, de que por lei decorrem direitos".

É importante destacar que a importância do fato não se restringe aos sistemas de direito intertemporal subjetivos que, como é o caso do brasileiro, limitam a retroatividade das leis à existência de direito adquirido. Também nos sistemas

1 A irretroatividade das Leis e o Direito Adquirido. São Paulo: Saraiva, 2000, p. 216.

2 Op. cit. p. 226.

3 Direito Intertemporal ou Teoria da Retroatividade das Leis. Rio de Janeiro: Editora Freitas Bastos, 1946, p. 38.

4 Op. cit. p. 25. 
objetivos, que impossibilitam a retroatividade da lei para alcançar as situações jurídicas concretas, é a ocorrência do fato previsto na situação jurídica abstrata que lhe transformará em concreta.

Logo, a partir do momento que um fato é capaz de transformar uma situação jurídica abstrata em concreta, tem-se que a lei não pode retroagir sobre esta, tal como defende Roubier, o principal expoente da teoria objetiva, cujo pensamento é muito bem sintetizado por Eduardo Espínola"

"A situação jurídica concreta, em oposição à abstrata, é o modo de ser que deriva, para uma pessoa determinada, de um ato jurídico ou de um fato jurídico, que, em proveito dessa pessoa ou em relação a ela, aplicou as regras de uma instituição jurídica, conferindo-lhe as vantagens e obrigações inerentes ao funcionamento da mesma instituição.

Em outras palavras: a situação jurídica abstraia é maneira de ser teórica, a situação jurídica concreta uma realidade positiva."

Dessa maneira, é fácil concluir que a $E C n^{\circ} 20 / 98$ já previu o fato idôneo para assegurar o direito nela previsto: a condição de servidor público na data da sua publicação. É exatamente por isso que não se trata de mera expectativa de direito, mas de direito adquirido em razão de fato aquisitivo previsto expressamente na Emenda Constitucional.

Não se discute que o direito à aposentadoria, tal como previsto na $\mathrm{EC} \mathrm{n}^{\circ} 20 / 98$, dependerá ainda do cumprimento de alguns requisitos por parte dos servidores interessados, tais como o preenchimento dos limites de idade, tempo no cargo e tempo de contribuição.

No entanto, é preciso considerar que o fato não precisa estar definitivamente constituído para ser considerado aquisitivo de direitos. Desde que o atendimento dos demais requisitos para a sua constituição dependa apenas do interessado, existe o direito adquirido, como demonstra Carlos Maximiliano, com base na lição de Gabba ${ }^{6}$ :

" $O$ direito adquirido compóe-se, em síntese, de dois elementos: o direito objetivamente considerado e facto aquisitivo, que transforma aquele, de objetivo em subjetivo ou individual.

(...)

O fato não definitivamente constituído produz direito adquirido, só em três casos: a) quando seja, por sua natureza, fatal, infalivel; b) quando não dependa o seu completamento senão do adquirente, conforme se dá na hipótese de verdadeira e própria condição; c) quando a aquisição tenha a sua raiz em anterior direito adquirido, de que seja simples desenvolvimento, ou transformação."

5 A Lei de Introdução ao Código Civil Brasileiro Comentada. Rio de Janeiro: Livraria Freitas Bastos, 1943, pp. 319-320.

6 Op. cit, pp. 44-45. 
Assim, poder-se-ia dizer, em síntese, que a $\mathrm{EC} \mathrm{n}^{\circ} 20 / 98$ previu dois tipos de fatos aquisitivos para as regras de transição nela contidas: (a) a condição de servidor público na data da sua publicação, fato já concretizado; e (b) o atendimento aos limites de idade, tempo no cargo e tempo de contribuição nela contidos.

Se o primeiro fato aquisitivo - condição de servidor público na data da publicação da emenda - decorreu automaticamente da $E C n^{\circ} 20 / 98$, resta saber se os demais fatos aquisitivos dependem exclusivamente de cada servidor pois, se a resposta for afirmativa, estar-se-á diante de hipótese de direito adquirido.

\section{A natureza jurídica e as finalidades das regras de transição não se compatibilizam com a possibilidade de revogação superveniente}

Como é de saber comum, o pressuposto do direito intertemporal é o de que o período de vigência das normas no tempo é indeterminado quanto ao seu fim, motivo pelo qual, sobrevindo uma norma superveniente, é necessário saber os efeitos desta sobre a norma anterior, inclusive no que diz respeito à preservação de situações ou direitos já constituídos sob a vigência da norma antecedente.

Não é sem razão que o art. $2^{\circ}$, da Lei de Introdução ao Código Civil, ao prever a regra geral de revogação das leis, afirma que "não se destinando à vigência temporária, a lei terá vigor até que outra a modifique ou revogue." Dessa forma, as leis de vigência temporária foram excetuadas da regra geral da revogação superveniente, em razão de já possuírem a sua vigência perfeitamente delimitada no tempo, tanto no que se refere ao início como também ao fim.

É exatamente esse o caso de uma norma de transição, que possui vigência temporária e objetivos de regular, de forma concreta, a passagem de determinada normalização jurídica para uma outra. Dessa maneira, a própria natureza jurídica de uma regra de transição, cuja vigência é temporária, é suficiente para demonstrar a manifesta inaplicabilidade da regra geral de revogação das leis, diante da circunstância especial de que as mesmas já têm a vigência delimitada no tempo.

Todavia, não é apenas a natureza jurídica de uma regra de transição que a toma insuscetível de ser revogada supervenientemente de acordo com o arbítrio do legislador. É a finalidade destas regras que impõe tal entendimento.

Não se pode esquecer que o direito intertemporal estrutura-se a partir da tensão entre a segurança jurídica, por um lado, e dinamicidade do direito, por outro. Dessa forma, o direito intertemporal visa a encontrar mecanismos que possibilitem o progresso do direito, a fim de que as leis possam acompanhar a evolução social, sem ignorar as situações ou direitos já constituídos e considerando, dentro do possível, as justas expectativas do que estavam submetidos à anterior regulação legal e orientaram vários de seus comportamentos em face desta.

De todos os mecanismos de que dispõe o direito intertemporal para resolver o conflito de leis no tempo, nenhum deles é mais idôneo e apto a contrabalançar os dois princípios envolvidos - segurança jurídica e dinamicidade - do que a utilização das leis de transição, que podem tomar a passagem de um sistema legal para o outro menos traumática, prestigiando não apenas os direitos adquiridos ou as 
situações jurídicas concretas, mas também a boa-fé e a justa expectativa de todos aqueles que se submeteram à regulação anterior na esperança de receberem a contraprestação prevista nas leis da época.

Roubier, que é certamente uma das maiores referências sobre o assunto, mostrou que o direito intertemporal não deixa de ser um método de "homeopatia jurídica" para resolver os conflitos das leis no tempo e que, dentre as soluções legislativas mais eficientes para esse propósito, deveria ser destacado o mecanismo das leis transição?

Com efeito, é da essência das leis de transição a conciliação de interesses particulares com a nova legislação, motivo pelo qual devem conter regras específicas para a solução dos conflitos, evitando, dessa maneira, os inúmeros problemas que decorrem da passagem de um sistema para o outro ${ }^{8}$.

É por essa razão que as leis de transição não estão sujeitas à regra geral da revogação das leis, pois têm como finalidade exatamente a de evitar o conflito de leis no tempo e não a de postergá-lo ou até mesmo aumentá-lo.

A partir do momento em que se admite que as leis de transição possam ser revogadas a qualquer momento, de acordo com as conveniências do legislador, estas deixam de fazer qualquer sentido no ordenamento jurídico. Se a sua finalidade era a de assegurar a passagem de um sistema para o outro, disciplinando as relações intermediárias em respeito às justas expectativas daqueles que guiaram os seus comportamentos com base no sistema anterior, é inequívoco que a revogação da lei da transição implicará uma total subversão dos seus objetivos e das suas finalidades.

Ademais, a possibilidade de que as leis de transição sejam revogadas sem nenhuma limitação faz com que as mesmas deixem de ser instrumentos para resolver conflitos de leis no tempo e tomem-se um fator complicador deste conflito, tomando a sua solução ainda mais tormentosa.

Se a finalidade da lei de transição é a de conciliar a segurança jurídica e a dinamicidade do direito diante de uma alteração legislativa, a sua revogação apenas poderá ocorrer mediante o comprometimento irremediável e inaceitável da segurança jurídica.

Veja-se, por exemplo, que, na edição da $\mathrm{EC}^{\circ}{ }^{\circ} 20 / 98$, muitos servidores públicos já haviam atendido grande parte dos requisitos previstos pelas normas constitucionais anteriores sobre a aposentadoria e, como não haviam adquirido o direito ainda, passaram a ser regidos por regras de transição. Estas, embora mais brandas do que as novas regras, continham requisitos mais severos do que os previstos na normatização anterior.

Com a EC n 41/2003, mesmo essas regras de transição previstas na $\mathrm{EC}^{\circ}$ 20/98 foram desconsideradas. E nada assegura que as novas regras de transição previstas pela $E C n^{\circ} 41 / 2003$ não venham a ser ignoradas no futuro por alguma outra emenda constitucional superveniente.

7 Les conflits de lois dans le temps, Paris: Libraire du Recueil Sirey, 1933, Tomo I, p. 32.

8 Roubier, op. cit. Tomo I, pp. 35-36. 
Afinal, a partir do momento em que se admite a completa subversão das finalidades de uma regra de transição, permite-se que estas estejam sujeitas apenas ao arbítrio do poder constituinte derivado, sem nenhum compromisso com a segurança jurídica.

Não se pode esquecer que, como já salientado no capítulo anterior, a EC $\mathrm{n}^{\circ}$ 20/98 condicionou a aquisição dos direitos nela previstos a dois fatos: (a) a condição de servidor na data da sua publicação, fato de incidência automática, e (b) o atendimento dos requisitos nela previstos, tais como limite de idade, tempo no cargo e tempo de contribuição.

E exatamente porque esses requisitos foram previstos em uma norma de transição, que tem a finalidade específica de disciplinar concretamente a situação e evitar o conflito de leis no tempo, é que os mesmos não podem ser alterados pelo Poder Legislativo, nem mesmo no exercício do poder constituinte derivado.

A hipótese é de existência de direito adquirido pois, apesar de a totalidade do fato aquisitivo não estar completa, tal aperfeiçoamento passou a depender apenas dos interessados, já que as regras de transição não estão sujeitas aos princípios gerais de revogação.

Ao assim não observar, a $E C n^{\circ} 41 / 2003$ violou o princípio da segurança jurídica e da proteção ao direito adquirido, ofendendo igualmente o princípio da proporcionalidade, tendo em vista que desconsidęrou abusivamente as regras de transição da anterior $\mathrm{EC} \mathrm{n}^{\circ} 20 / 98$.

\section{A EC $n^{\circ} 20 / 98$, ao prever as regras de transiçāo, criou verdadeiros direitos} adquiridos sob condição, o que é perfeitamente possível e legitimo

Esclarecidos a natureza jurídica e os objetivos de uma regra de transição, é fácil observar que a $E C n^{\circ} 20 / 98$, conferiu aos servidores ocupantes de cargos na data da sua publicação verdadeiros direitos adquiridos à aposentadoria, desde que cumpridos os requisitos nela previstos. Trata-se, na verdade, de direito adquirido sob condição a ser implementada pelos servidores.

Com efeito, a figura do direito adquirido sob condição é prevista expressamente na Lei de Introdução ao Código Civil, ao afirmar, no art. $6^{\circ}, \S 2^{\circ}$, que "consideram-se adquiridos assim os direitos que o seu titular, ou alguém por ele, possa exercer, como aqueles cujo começo do exercício tenha termo pré-fixo, ou condição pré-estabelecida inalterável, a arbítrio de outrem."

Como já se viu amplamente no capítulo anterior, as normas previstas em normas de transição, por não estarem sujeitas às regras gerais de revogação das leis, não podem ser alteradas ao arbítrio do legislador. Consequientemente, passaram a integrar o patrimônio jurídico de todos aqueles que eram servidores públicos na data da publicação da $E C \mathrm{n}^{\circ} 20 / 98$, estando a eficácia das mesmas sujeita à condição de o servidor cumprir os requisitos nela previstos. 
A doutrina, por sua vez, nunca vislumbrou nenhum problema na existência de direitos adquiridos sujeitos à condição suspensiva. Eduardo Espínola, por exemplo, mostra que, para efeitos do direito intertemporal, a condição se equipara ao termo, possibilitando desde já a aquisição do direito, nos termos da seguinte lição"

"Ai se explica: - considera-se adquirido o direito - cujo começo de exercício tenha condição preestabelecida, inalterável a arbítrio de outrem -. Entretanto, o art. 118 do Código Civil dispõe que - "subordinando-se a eficácia do ato à condição suspensiva, enquanto esta não se verificar, não se terá adquirido o direito a que ele visa." É irrecusável a contradição. $O$ que daí se poderá deduzir é que o legislador, simplesmente para os efeitos do princípio da irretroatividade das leis, equiparou a condição suspensiva ao termo inicial; considerando, tão somente para esses efeitos, como adquirido o direito dependente de uma condição suspensiva insusceptível de alteração a arbítrio de outrem."

No mesmo sentido, destaca-se a opinião de Carlos Maximiliano ${ }^{10}$ :

"Não se confunde com expectativa a condição nem o termo; pois o interesse que se acha subordinado a qualquer destas duas modalidades constitui direito verdadeiro: a condição retroage licitamente; a expectativa, quanto aos seus resultados, depende da vontade de uma pessoa estranha, o que não se dá com o termo ou a condição."

Já para Limongi França, os direitos sujeitos à condição podem ser adquiridos, como modalidades que são dos chamados direitos de aquisição complexa ${ }^{11}$ :

"Conforme foi visto na seção anterior, no caso do termo, não há dúvida sobre a aquisição desde logo, suspendendo-se apenas o seu exercício. Já na hipótese de condição, a despeito da questão que se coloca, a aquisição se tem por ab initio, pois verificado o evento, seus efeitos retrogem à data do fato.

A lei aplicável, conforme foi demonstrado, é a antiga."

Daí concluir Limongi França que "são adquiridos Direitos condicionados, tanto sob condição resolutiva como suspensiva." 12

Restaria apenas a discussão concernente à possibilidade de direitos adquiridos sob condição no direito público. A pesquisa realizada logrou encontrar apenas uma

11 Op. cit, p. 242.

12 Op. cit., p. 297. 
opinião doutrinária sobre o tema. Trata-se de artigo do Professor José Carlos Moreira Alves, que assim examina o assunto ${ }^{13}$ :

"Pois bem, o que interessa aqui é o problema do direito adquirido condicional e do direito adquirido a termo, e a pergunta que surge é esta: há direito adquirido condicional? Há direito adquirido a termo? Pela Lei de Introdução, que é considerada constitucional neste ponto, não há dúvida de que existe direito adquirido condicional, que é aquele que já se exauriu mas cujo exercício depende da realização de uma condição, ou o direito adquirido a termo que é aquele que já se adquiriu mas cujo efeito só começa a produzir no momento em que ocorre o termo.

A pergunta que surge é a seguinte: isso se aplica também a direito público? Em geral não se encontra, eu, pelo menos, nunca encontrei em livro brasileiro algo a respeito, e em livro estrangeiro, só encontrei um autor estrangeiro, Frederico Cammeo, que tem um tratado de Direito Administrativo na ltália, e que sustenta muito bem, ao meu ver, e o próprio STF já começa a adotar essa orientação, que esse direito adquirido condicional e o direito adquirido a termo não se aplicam com relação ao direito público por uma circunstância. Porque, se aplicar, nós teríamos um direito adquirido a regime jurídico, tendo em vista a circunstância de que um indivíduo, quando ingressa no serviço público, eleja tem aquilo que nós consideramos expectativa, e que seria já um direito adquirido sob condição, por que é uma condição inalterável ao arbítrio de outrem, segundo a Lei de Introdução ao Código Civil. E aí se pergunta, nesse caso, nós teriamos uma condição inalterável ao arbítrio de outrem? De certa forma, teríamos, porque ela poderia ser alterada pela lei nova."

Como se pode observar, o Professor José Carlos Moreira Alves afastou a possibilidade de aceitar direitos adquiridos sob condição no direito público, apreciando a hipótese usual das leis de tempo indeterminado. E a razão de ser é muito simples: se o regime jurídico pode ser alterado, é inequívoco que não se estaria diante de condição "inalterável ao arbítrio de outrem". Essa seria a regra geral no direito público.

No entanto, a situação ora examinada é distinta, tendo em vista que se trata de normas de transição, que não previram regime jurídico abstrato e suscetível de alteração de acordo com as regras gerais de revogação. Pelo contrário, exatamente para o fim de evitar o conflito de leis no tempo, as regras de transição contidas na $E C n^{\circ} 20 / 98$ previram requisitos concretos e determinados para a aquisição do direito e que, exatamente por isso, não podem ser alterados "ao arbítrio" do legislador constituinte derivado.

É por essa razão que as normas de transição são uma exceção à regra geral de que não existem direitos adquiridos sob condição no direito público. Se a regra é

13 "Direito Adquirido", In: Fórum Administrativo. Direito Público, ano 2, n 15, maio de 2002. pp. 579-587, p. 584. 
inteiramente pertinente no que se refere às leis abstratas e com vigência por tempo indeterminado, não se mostra cabível diante de regras de transição, que visam a solucionar problemas concretos de direito intertemporal e de vigência determinada.

Isso já foi amplamente demonstrado em parecer do Professor José Afonso da Silva, do qual se destaca o seguinte trecho ${ }^{14}$ :

“4) Pode a emenda à Constituição suprimir direito assegurado em norma constitucional, a quem no momento de sua edição preenchia o requisito fundamental de ter ingressado regular e anteriormente em cargos efetivos da administração pública - arts. $2^{\circ}$ e 11 da PEC que revogam o art. $8^{\circ} \mathrm{da}$ Emenda Constitucional $n^{\circ}$ 20/98)?

Não. A indagação se prende ao conteüdo do art. $8^{\circ}$ da EC-20/I998. Esse artigo, como o art. $6^{\circ}$ da PEC, fez uma ressalva de direito para ser exercido na vigência da Emenda, sem maiores exigências. Assim, em verdade, o texto transformou expectativa de direitos em direito subjetivo. $O$ texto do art. $8^{\circ}$, em tela, conferiu um tipo de direito adquirido ao regime de aposentadoria, na medida em que preservou o direito de aposentar-se nas mesmas condições vigentes antes de sua promulgação. A natureza da norma, como disse no curso do parecer, é a de converter expectativa de direito em direito subjetivo para ser exercido no futuro, sob a condição do preenchimento dos requisitos indicados, o que significa que, vindo novas normas, esse direito não pode ser desfeito, porque, sendo direito subjetivo, passa a se adquirido em face da superveniência das novas normas. Se não for assim, estar-se-á diante de uma verdadeira fraude constitucional, numa brincadeira de dar e retirar incessante, ao sabor dos detentores do Poder. Normas constitucionais, mesmo provenientes de Emendas à Constituição, não podem ser manobradas assim como um boneco de cera, ao sabor dos donos do Poder. em prejuizo dos direitos constituidos."

É por essas razões que a $\mathrm{EC}^{\circ} 41 / 2003$, ao revogar o art. $8^{\circ}$, da $\mathrm{EC}^{\circ} 20 / 98$, prevendo novas regras de transição para os servidores detentores de cargos públicos na data da publicação desta, violou o direito adquirido dos mesmos.

5. O direito à aposentadoria é de aquisição complexa: os fatos aquisitivos constituídos sob a égide de uma norma constitucional não podem ser desconsiderados pela norma superveniente

Ainda que não se entendesse possível a existência de direitos adquiridos sob condição no direito público, seria forçosa a conclusão de que a EC $n^{\circ} 41 / 2003$ retroagiu indevidamente, violando o art. $5^{\circ}, \mathrm{XXXVI}$, da Constituição.

14 Parecer sobre o tema solicitado pela Associação Nacional dos Membros do Ministério Público CONAMP e pela Associação Nacional dos Magistrados Brasileiros - AMB. 
Isso porque a referida Emenda ignorou completamente a peculiaridade de que o direito à aposentadoria é um dos direitos de aquisição complexa, assim definidos "aqueles que, para se adquirirem, dependem da perfeição de elementos separados ou sucessivos." 15

De fato, nem todos os direitos são adquiridos de forma instantânea, como mostra Limongi França a partir da lição de Gabba ${ }^{16}$ :

"Contemporaneamente, ao tratar da perfeição dos fatos aquisitivos, Gabba distingue os fatos simples dos complexos: simples são aqueles que se completam em um só instante; complexos, os que se compóem de partes que se realizam separadamente, e a distância, uma da outra.

A seguir, acrescenta o eminente mestre italiano: "De três modos podem ser complexos os fatos aquisitivos, a saber: a) quando uma mesma pessoa empreenda uma série de atos em um periodo mais ou menos longo de tempo; b) quando duas ou mais pessoas devam empreender, cada qual separadamente, um fato próprio e distinto; e c) quando a um determinado ato de uma pessoa se deva ajuntar um acontecimento que não está em seu poder" (p. cit.).

O autor cita, como exemplos, respectivamente, o usucapiāo, a sucessão testamentária e a transmissão unilateral de direitos, sob condição.

Quanto à questão de se saber a que altura existe direito adquirido, em tais circunstâncias, assinala que não é possível resolver-se a priori, dependendo de se apresentar em cada caso "um especial caráter idôneo a tal efeito" (p. 229).

E explica: "Este caráter pode ser um dos seguintes: a) que o fato ainda não verificado seja infalível (immancábile); $b$ ) que não mais esteja no poder. daquele em confronto do qual o direito é adquirido, impedir o fato que falta, para que se aperfeiçoe a transmissão; c) que a aquisição a que deve dar lugar a realizaçāo do fato não realizado (il compimento Del fatto incompiuto) tenha a sua raiz em um anterior direito adquirido, do qual seja um desenvolvimento ou uma transformação. (...)

Autores que não esposam a Doutrina Clássica também cuidaram da matéria, dentre eles Planiol e Roubier. $O$ resumo dos ensinamentos deste último se encontra no art. 28 do Anteprojeto, referente à matéria, apresentado à Comissão do Código Civil Francês, cujo teor é o seguinte: "Quando há concurso de situações jurídicas, oriundas de fontes diferentes, cada qual destas situações deve suportar a competência da lei que corresponde ao momento de sua constituição, dos seus efeitos ou de sua extinção, segundo o momento em que a lei nova deve atender a esta situação."

15 LIMONGI FRANÇA, op. cit., p. 238.

16 Op. cit. pp. 238-240. 
Portanto, há que se distinguir os direitos de aquisição complexa das meras expectativas de direito. Mais uma vez, recorre-se à lição de Limongi França ${ }^{17}$ :

"Ora, uma vez que estamos tratando das fronteiras do Direito ADQUIRIDO. o que interessa não é a complexidade dos fatos, senão da AQUISIÇÃO dos diversos Direitos. Daí propormos que se fale, não em fatos complexos, mas em direitos de aquisição complexa.

(...)

De nossa parte, partindo da summa divisio de Gabba, propomos que se distingam ab initio: Direitos de aquisição simples e Direitos de aquisição complexa.

Direitos de aquisição simples são aqueles que se auferem em conseqüência de um elemento fundamental único, seja ela a lei ou um fato jurídico. Já com relação aos Direitos de aquisição complexa, isto é, os que decorrem da realização de vários elementos, não poucas são as questões que oferecem. no que tange ao momento em que a sua aquisição se efetiva.

Dentre os direitos de aquisição complexa, Limongi França destaca a os direitos de aquisição sucessiva, como "aqueles que se conseguem mediante o decurso de um certo lapso de tempo." 18

O exemplo clássico de direito de aquisição sucessiva seria exatamente o direito à aposentadoria, como se observa na continuação da sua lição ${ }^{19}$ :

“c) Direitos de Aquisição Sucessiva. Trata-se, como vimos, daqueles que se obtêm mediante o decurso de um lapso de tempo. É o caso da prescrição, do Direito à aposentadoria, da maioridade, etc. Não se confundem com os Direitos a termo. Nestes últimos, a perfeição depende da mera incidêncic: de um evento futuro e certo; naqueles, o Direito se adquire dia-a-dia, com o correr sucessivo do prazo.

A retroação total, conforme o preceito de Muller, incorreria em ignorar a patrimonialidade do prazo já decorrido. Por outro lado, a aplicação integral da lei antiga (Código francês, art. 3.381), implicaria em considerar adquirido um Direito cuja perfeição estava na dependência de elementos aincia não verificados.

A solução, pois, parece encontrar-se na aplicação imediata da lei, considerando-se válido o lapso já decorrido, e computando-se o lapso por escoar de acordo com a lei nova."

A conseqüência principal do reconhecimento dos direitos de aquisição sucessiva diz respeito à impossibilidade de se ignorar o prazo já vencido, pois os mesmos se

17 Op. cit., pp. 241-242.

18 Op. cit., p. 242.

19 Op. cit., p. 243. 
adquirem a cada dia e não são meras expectativas. Existe, portanto, uma patrimonialidade do prazo já corrido ${ }^{20}$, que não pode ser subtraída do titular do direito.

Em outras palavras, poderia a norma superveniente até alterar o modo de aquisição do direito, desde que respeitasse os fatos aquisitivos ocorridos sob a égide da norma anterior, de acordo com os efeitos que lhe eram atribuídos por esta.

Assim, se o servidor já havia cumprido metade do tempo (50\%) para se aposentar de acordo com determinada legislação e este tempo é aumentado, o servidor deve suportar o aumento do tempo mas tão somente no que se refere à metade do tempo que lhe faltava (os $50 \%$ restantes). Em outras palavras, o servidor precisa ter resguardado o tempo proporcional já cumprido, ainda que o tempo total seja aumentado, como fica claro na lição de Limongi França 21 :

"Ora, parece-nos que, diante dos elementos fundamentais do nosso sistema de Direito Intertemporal, não se pode negar uma certa patrimonialidade relativa ao decurso de prazo, ainda que incompleto. Com efeito, se isto se apoia, de um lado, na recta ratio, do que é demonstração o art. 2.281 do Código Francês, cuja autoridade não é menor do que a daqueles que pensam o contrário, do outro, é preciso atentar para a índole do nosso Ordenamento e da Doutrina em geral que reconhece essa patrimonialidade aos próprios Direitos condicionais.

Não nos escapa o fato de que não há analogia entre o Direito Condicional $e$ o Direito de aquisição sucessiva. $O$ que existe, sim, fora uma afinidade hábil a justificar a ponderação de que, se naquele se aceita uma patrimonialidade que pode ser frustrada com a não incidência da condição, com boas razões a mesma se deve admitir neste, porquanto a sua aquisição se realiza dia-a-dia, de modo progressivo, e cada vez menos imperfeito. Por outro lado, embora também seja gradativa a perda do Direito da outra parte, enquanto o respectivo lapso não se completar, o referido Direito ainda lhe pertence.

Desse modo, a regra do efeito imediato deve buscar um corolário, segundo o qual não se desatendam os interesses de ambos os sujeitos, sob pena de retroação. Ora, tal corolário, a nosso ver, consistiria no estabelecimento de uma proporção entre o prazo anterior e o da lei nova, de tal forma que sempre fosse assegurado à parte contrária um prazo para exercer as suas defesas. Assim, por exemplo, se o prazo de trinta anos vem a ser abreviado para quinze, e faltavam dez anos para se completar, o periodo faltante passaria a ser de cinco."

A necessidade de que os fatos ocorridos sob a vigência de uma norma sejam incorporados ao patrimônio do servidor de acordo com a valoração jurídica que incidia na época é igualmente apontada por Carlos Maximiliano, nesses termos ${ }^{22}$ :

Op. cit., p. 246.

22 Op. cit., p. 49. 
"Um fato constituído por muitos outros sucessivos fica subordinado às normas vigentes na época em que foi completado, desde que haja sido produzido sob o regime de lei anterior com o propósito de aquisição de direito. (...)

A regra geral é a seguinte: as conseqüencias materiais do ocorrido sob o império da lei anterior, norma positiva, regem-se de acordo com a lei em cuja vigência surgiu o fato ou a relação jurídica respectiva."

O mesmo raciocínio se aplica aos sistemas de direito intertemporal objetivos, como explica Eduardo Espínola com base na lição de Roubier ${ }^{23}$ :

"Mas, nos momentos sucessivos de uma situação jurídica, há a distinguir a fase dinâmica - a da constituição (e também da extinção) e a fase estática - a do momento em que a situação constituida produz os seus efeitos.

A constituição de uma situação jurídica opera-se por meio de fatos, voluntários ou não; alguns desses fatos são considerados como suscetiveis de produzir a situação jurídica, outros não; a lei nova não pode compreender os fatos propriamente constitutivos (ou extintivos), anteriores à sua vigência, sem ser retroativa. Por conseguinte, as leis relativas aos modos de constituição, ou de extinção duma situação jurídica, não podem, sem retroatividade, por em questão a eficácia ou ineficácia jurídica de um fato passado."

Isso porque Roubier igualmente fazia a distinção entre as situações jurídicas de aquisição imediata daquelas cuja aquisição se submetia a um período mais longo. $\mathrm{E}$ concluía no sentido de que os fatos anteriores à lei nova apenas poderiam ser considerados, para efeitos da situação jurídica concreta, de acordo com a lei anterior. Mais uma vez, recorre-se à excelente síntese de Eduardo Espínola a respeito da obra do ilustre jurista francês ${ }^{24}$ :

"A formação sucessiva de uma situação juridica tem, para o direito transitório, grande importância: só se consideram as leis em vigor nos diferentes momentos da formação, sem se levar em conta a vigente no tempo intermediário (media têmpora non nocent). Para determinar a ação das leis novas relativas aos modos de constituição (ou de extinção) das situações jurídicas, cumpre verificar: se a constituição não se realizou nem mesmo foi começada na vigência da lei antiga, caso esse simples, em que se aplica a lei nova, sem que se possa propriamente falar em conflito de leis; se a constituição se realizou completamente de modo instantâneo, ou por atos sucessivos, caso em que a lei nova só retroativamente pode ser aplicada; ou se a constituição está em curso, quando aparece a lei nova que vem modificar

23 Op. cit., p. 323.

24 Op. cit., pp. 324-326. 
as condições de constituição, caso esse que apresenta as mais sérias dificuldades.

(...)

Quanto às situações juridicas em curso de constituição, ou de extinção, o princípio é, evidentemente, que, enquanto uma situação jurídica não está constituida ou extinta, a lei nova pode modificar as condições da sua constituição ou da sua extinção, sem que haja efeito retroativo. Uma restrição, porém, a fazer: pode acontecer que já se tenham reunido um ou vários elementos com valor jurídico particular, em relação à formação em curso; a lei nova não poderia, sem retroatividade, atingir esses elementos na sua condição de validade e nos efeitos que já produziu.

"Em face de uma situação jurídica em curso de constituição, ou de extinção, as leis, que governam a constituição ou extinção duma situação jurídica, não podem, sem retroatividade, atingir os elementos já existentes, que fazem parte (ou obstáculo) desta constituição ou extinção, enquanto têm valor jurídico próprio, e devem respeitar esse valor jurídico, quer o caso seja da validade ou dos efeitos juridicos, que tais elementos tiverem produzido."

Para não haver qualquer dúvida sobre o pensamento de Roubier, vale destacar o trecho no qual o mesmo explica as conseqüências da irretroatividade sobre as situações jurídicas cujo momento de constituição requer a presença de elementos sucessivos $^{25}$

"Lê cycle de développement d'une situation juridique comprend trois moments, le moment de sa constitution, le moment de ses effects et le moment de son extinction. Le premier et le troisième moments représenten la dynamique, le deuxième la satatique de cette situation.

(...)

La période de constitution (ou d'extinction) d'une situation juridique peut avoir une durée variable:

a) II y a tout d'abord des situations juridiques qui se constituent (ou s'eteignent) en un seul moment, único momento.

(...)

b) Mais il y a des situations juridiques don't la constitution (ou l'extinction) suppose au contraire une certame période de temps. Elles sont d'alleurs de plusierus sortes:

$1^{\circ}$. II y a d'abord des situations juridiques, dont la constitution requiert un certain état de fait continu dans la durée. (...)

$2^{\circ}$. Il y a aussi des situations juridiques, dont la constitution requiert la presence d'élements successifs, intervenant à des moments différents de la durée.

(...)"

Op. cit., Tomo I, pp. 381-383. 
Apesar de considerar que as situações jurídicas em curso de constituição representam uma das matérias mais delicadas do direito intertemporal, Roubier é incisivo ao repelir que a lei superveniente negue os efeitos já constituídos sob a lei anterior ${ }^{26}$ :

"Le príncipe est, évidemment, que, tant qu'une situation juridique n'est pás constituée (ou éteinte), la loi nouvelle peut modifier les conditions de sa constitution (ou de son extinction) sans qy'il y ait effet rétroactif; il y a seulement effet immédiat de la loi. Une restriction cependant doit être apportée: il se peut qu'un ou plusieurs elements ayant une valeur juridique particuliére au regará de la formation em cours, soient dejá reunis; la loi nouvelle ne pourrait, sans rétroactivité, atteindre ces élements dans leurs conditions de validité et dans les effets qu'ils ont dejá produits."

E assim conclui o jurista francês sobre os limites da lei nova em relação às situações jurídicas em curso de constituição ${ }^{27}$ :

"Lorsqu'une situation juridique est en cours de constitution (ou d'extinction), les lois nouvelles relatives à cette constitution (ou extinction) ont un effet immediate, c'est-à-diré qu'elles s'appliquent à competer de leur entrée em vigueur, respectant seulement les elements autérieurs de cette situation em cours, em tant qu'ils peuvent avoir une valor juridique distinte (...)"

Na doutrina nacional, deve ser igualmente lembrado o notável parecer de Celso Antônio Bandeira de Mello sobre o tema ${ }^{28}$.

"Comecemos, todavia, por observar que fatos pretéritos, mas que se encartam em situações ainda em curso, podem e devem ser tratados de maneira a se lhes reconhecer a significação jurídica que tiveram em face da regra precedente, sem com isto afrontar-se a regra nova ou negar-lhe imediata vigência. Basta compatibilizá-los de sorte a atribuir a tudo que passou o valor de jurídico que se lhe correspondeu até o tempo da sobrevinda da nova lei e atribuir a auto que transcorrerá a partir desta última os efeitos que resultam de seu tempo de império. Vale dizer: reconhece-se - o que é incontendivel - a força modificadora da regra nova em relação ao regime anterior, sem, com isto, fazer "tabula rasa" da disciplina pretérita.

E dizer: consideram-se os fatos atuais, consoante a significação que lhes atribui o dispositivo atual, $e$ absorvem-se os fatos vencidos, segundo o significado que lhes outorgava a lei do tempo. Em uma palavra: faz-se

26 Op. cit., pp. $387-388$.

27 Op. cit., Tomo II, p. 762.

28 Parecer sobre o tema solicitado pela Associação Nacional dos Membros do Ministério Público - CONAMP e pela Associação Nacional dos Magistrados Brasileiros - AMB. 
reconhecimento, não apenas nominal, mas real, de que uma situação foi apanhada por duas normas, de que esteve sob regência de dois preceitos, pois seu caráter continuado - e não instantâneo - levou-a a transitar pelo tempo e ser interceptada por diplomas diferentes. (...)

Apliquemos estes preceitos exegéticos ao caso da aposentação. Esta é direito que só se completa depois de totalmente perlongada a dilação temporal prevista pela regra concessiva do beneficio. De outro lado, é logicamente impossivel chegar-se ao seu termo sem percorrer, passo a passo, todo o itinerário cronológico conducente ao final do prazo. Quanto entre o inicio e o encerramento do prazo para a fruição da aposentadoria incidem duas normas que assinalam periodos diversos para o momento aquisitivo, os eventos que se passaram sob a regra antiga e os que ocorrem sob o império da nova têm significações diferentes perante o Direito.

Segue do exposto que, sob o império de uma dada regra, que fixava em tantos anos $(25,30,35$ anos) de serviço o prazo para aposentação de servidor do sexo masculino, cada ano transcorrido tinha, perante o Direito, uma significação relativa (ao todo) perfeitamente identificável, reconhecível, independentemente da circunstância de envolver ou não direito adquirido.

Esta significação a que se aludiu corresponde ao valor, à importância, em sintese, ao relevo, que a ordem normativa atribui ao periodo de trabalho transcorrido em relação às possibilidades de se implementar a aposentadoria facultativa.

Em termos concretos: sob o império da Constituição de 1946, por exemplo, um ano de serviço correspondia a 1/30 avos do prazo para a aposentação do servidor do sexo masculino; 15 anos de serviço correspondiam a 15/30 avos, ou seja, metade do periodo necessário para aposentação a pedido.

De nenhum modo se contém nessa assertiva, de obviedade inconteste, a afirmação de que o funcionário haveria, por tal razão, adquirido o direito de se aposentar com 30 anos de serviço, se não os houvesse completado e sobreviesse preceito constitucional novo, dilatador do prazo, como viria a ocorrer.

$O$ asserto que se faz contém em si mesmo nem mais nem menos do que a seguinte proposição: cada ano de serviço possui uma significação de direito perante a norma então vigente. Esta significação é a relação entre o período vencido e o periodo total requerido para que se integralize o direito a se aposentar. A superveniência de outra norma encontra significações já existentes e, dentre elas, está a que se aludiu. Por força das disposições novas certamente o servidor não poderá se aposentar antes de 35 anos de serviço. mas tais disposições não podem desconstituir o significado juridico que os 20 anos passados tiveram sob o império da lei do tempo em que transcorreram sem com isto estarem incursas em retroação. Ou seja: se ele tinha, pois, 2/3 do tempo necessário para a aposentação, ele continuará a ter estes $2 / 3$, já agora dos 35 anos que passaram a ser requeridos." 
Como bem advertiu Celso Antônio Bandeira de Mello, "recusar aos fatos passados o relevo que um dia tiveram perante uma norma equivale a recusar-lhes a única densidade que possuiam perante o Direito."

Dessa maneira, ainda que se cogitasse que as regras de transição previstas na EC $n^{\circ} 20 / 98$ não criaram direitos adquiridos para os servidores por ela contemplados, seria forçosa a conclusão de que, em razão de a aposentadoria ser um direito de aquisição complexa e sucessiva no tempo, não poderia a $E C n^{\circ} 41 / 2003$ simplesmente desconsiderar todos os fatos aquisitivos ocorridos sob a vigência da anterior $E C n^{\circ}$ 20/98.

Mas foi exatamente o que fez a referida $\mathrm{EC}^{\circ}$ 41/2003: criou regras novas, desconsiderando todos os fatos aquisitivos ocorridos sob a vigência da EC $n^{\circ} 20 / 98$, subtraindo-lhes toda a eficácia que foi legitimamente adquirida até a sua revogação.

Mesmo no que se refere aos limites de idade e de tempo de contribuição, embora o art. $2^{\circ}$, da $E C n^{\circ} 41 / 2003$, tenha mantido os mesmos limites previstos na anterior EC $n^{\circ} 20 / 98$, previu um redutor no valor dos proventos de todos aqueles que pretenderem se aposentar com base nos limites anteriores. É o que se depreende do seu $\S 1^{\circ}$, assim redigido:

“ $\$ 1^{\circ} \mathrm{O}$ servidor de que trata este artigo que cumprir as exigências para aposentadoria na forma do caput terá os seus proventos de inatividade reduzidos para cada ano antecipado em relação aos limites de idade estabelecidos pelo art. $40, \S 1^{\circ}, I I I$, a, e $\S 5^{\circ}$ da Constituição Federal, na seguinte proporção:

I- três inteiros e cinco décimos por cento, para aquele que completar as exigências para aposentadoria na forma do caput até 31 de dezembro de 2005;

II - cinco por cento, para aquele que completar as exigências para aposentadoria na forma do caput a partir de $I^{\circ}$ de janeiro de 2006."

Em outras palavras e utilizando-se da expressão popular, a EC n 41/2003 "dá com uma mão e tira com a outra", na medida em que, para exercer o direito de se aposentar com os limites de idade previstos na EC $n^{\circ} 20 / 98$, o servidor sofrerá uma redução tão grande em seus proventos que isso impossibilitará o exercício desta opção.

Não é demais lembrar que as regras de transição previstas na EC $n^{\circ} 20 / 98$ possibilitavam a aposentadoria dos homens com 53 anos e das mulheres com $48 \mathrm{e}$ que os limites previstos pela atual EC $n^{\circ} 41 / 2003$ são de 60 anos de idade para homens e 55 anos para a mulher. Assim, o limite de idade mínima para a aposentadoria foi elevado em 7 anos tanto para homens como para mulheres.

Caso pretendam se aposentar com os limites de idade previstos na EC $n^{\circ} 20 / 98$, os servidores terão que suportar a diminuição dos seus proventos correspondente a 7 vezes o valor dos coeficientes previstos nos incisos I e II, do $\S 1^{\circ}$, do art. $2^{\circ}$, da EC $n^{\circ} 41 / 2003$. Isso implicará uma redução dos proventos de $24,5 \%$ ( 7 anos $\times 3,5 \%$ ) 
em relação aos servidores que reunirem as exigências para a aposentadoria até 31.12 .2005 (inc. I) e uma redução dos proventos de 35\% (7 anos x 5\%) em relação aos servidores que reunirem as exigências para a aposentadoria a partir de 01.01.2006 (inc. II).

A redução dos proventos é tão significativa que impossibilita, na prática, que qualquer servidor opte por se aposentar com base nos limites de idade previstos nas regras de transição da EC n $n^{\circ} 20 / 98$.

$\mathrm{O}$ que se pode observar é que a $\mathrm{EC} n^{\circ} 41 / 2003$ não respeitou os fatos aquisitivos anteriores à sua edição, o que apenas poderia ocorrer caso a mesma reconhecesse eficácia jurídica à disciplina da EC n $20 / 98$ pelo menos até a data em que foi revogada.

Mas não foi isso que ocorreu. $A E n^{\circ} 41 / 2003$, desconhecendo por completo que a aposentadoria é um direito de aquisição complexa e sucessiva no tempo, previu uma nova disciplina sem reconhecer a eficácia dos fatos aquisitivos legitimamente incorporados ao patrimônio jurídico dos servidores anteriormente à sua edição, especialmente no que se refere aos limites de idade e de contribuição.

Assim, é nítida a violação ao princípio do direito adquirido que, nos casos de direitos de aquisição sucessiva, como é a aposentadoria, resguarda contra a aplicação da lei nova pelo menos os fatos aquisitivos já aperfeiçoados sob a égide da legislação anterior.

\section{Considerações finais}

Como se viu, a EC n² $20 / 98$ previu em favor dos servidores ocupantes de cargos na data da sua publicação verdadeiros direitos adquiridos sob condição e não apenas expectativas de direitos. Com efeito, o primeiro fato aquisitivo decorreu automaticamente da $\mathrm{EC} \mathrm{n}^{\circ} 20 / 98$ - a condição de servidor público na data da publicação da emenda - e os demais fatos aquisitivos dependem exclusivamente de cada servidor, em razão de terem sido previstos em regra de transição.

Ao desconsiderar que as leis de transição não estão sujeitas à regra geral da revogação das leis, pois têm como finalidade exatamente a de evitar o conflito de leis no tempo e não a de postergá-lo ou até mesmo aumentá-lo, a referida EC $\mathrm{n}^{\circ}$ $41 / 2003$ agiu de forma abusiva e desproporcional, com manifesto desvio de finalidade e com ofensa ao devido processo legal em seu sentido material, que igualmente se aplica ao poder constituinte derivado.

Ainda que afastadas as conclusões já expostas, teria a EC $n^{\circ} 41 / 2003$ que respeitar o tempo proporcional para a aposentadoria já cumprido pelos servidores de acordo com o art. $8^{\circ}$, da $E C n^{\circ} .20 / 98$, inclusive para o fim de considerar tal tempo para efeito do valor dos proventos, tendo em vista que o critério de cálculo dos mesmos foi igualmente modificado.

São por essas razões que a $E C n^{\circ} 41 / 2003$ mostra-se, nesse aspecto, manifestamente inconstitucional, não apenas por ter modificado as regras de transição previstas 
na EC $\mathrm{n}^{\circ} 20 / 98$, mas, e principalmente, por ter desconsiderado a eficácia jurídica dos fatos aquisitivos ocorridos sob a égide desta.

Conseqüentemente, mesmo que se afastasse o nítido direito adquirido concedido aos servidores pelo art. $8^{\circ}$, da EC $n^{\circ} 20 / 98$, seria forçosa a conclusão de que os mesmos teriam direito a ver preservada a eficácia dos fatos aquisitivos legitimamente incorporados ao seu patrimônio jurídico enquanto vigente a $\mathrm{EC} \mathrm{n}^{\circ} 20 / 98$, especialmente no que se refere aos limites de idade, tempo no cargo e tempo de contribuição. 


\section{A Teoria Geral do Direito e o Marxismo}

E. B. Pasukanis

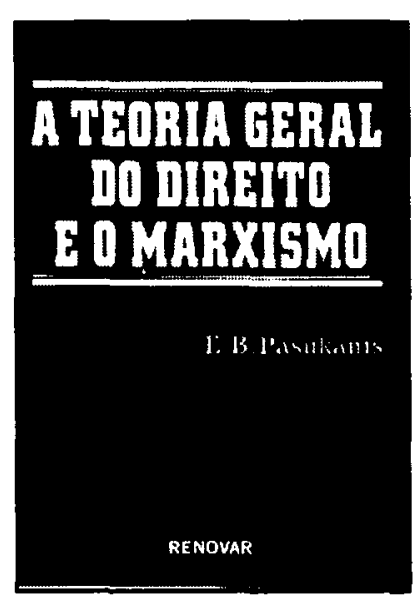

Obra indispensável para todos que pensam o Direito de forma crítica e democrática. $O$ autor realiza sua investigação partindo do pressuposto de que o Direito é uma forma necessária da sociedade capitalista e que surge em conseqüência de determinado nível de desenvolvimento das forças produtivas e das relaçōes daí decorrentes. Este livro reveste-se de real importância aos estudiosos do Direito, que terão em mãos um instrumento capaz de propiciar aos setores democráticos da sociedade uma nova visão do fenômeno jurídico.

$\begin{array}{lll}\text { Ref. 0015 } & \text { Brochura } & 378 \text { págs. } \\ \text { Form. } 14 \times 21 & 1989 & \end{array}$

\section{Cartas Constitucionais Império, República \& Autoritarismo (Ensaio, Crítica e Documentação)}

Neste livro, o autor examina, com o indispensável olhar crítico, alguns dos momentos mais densamente significativos dessa história, tal como ela se refletiu nas cartas constitucionais.

Ref. 131

Form. $14 \times 21$

Brochura 1997

Marcello Cerqueira

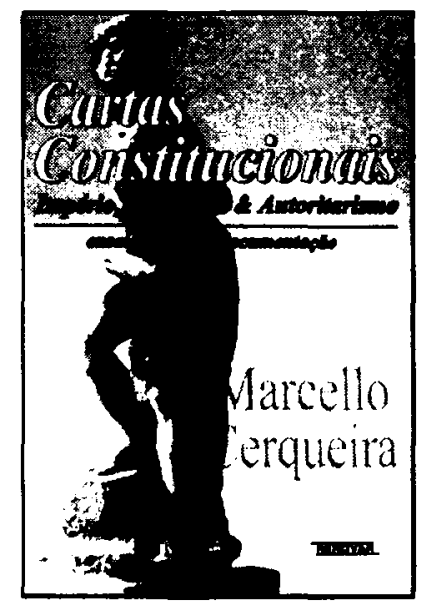

